\title{
PENGARUH REKRUITMEN, PENGEMBANGAN KARIR, DISIPLIN KERJA DAN MOTIVASI KERJA TERHADAP KINERJA KARYAWAN DINAKERTRANSDUK PROVINSI JATENG
}

\author{
Heru Sri Wulan ${ }^{1}$, Leonardo Budi Hasiholan ${ }^{2}$ \\ Universitas Pandanaran, Semarang \\ ${ }^{1}$ wulanarso76@gmail.com \\ ${ }^{2}$ leonardobudihas@yahoo.com
}

\begin{abstract}
Policies to improve employee performance need to be analyzed further. In this study will analyze the effect of recruitment, career development, work discipline and work motivation on employee performance at Dinakertrasduk, Central Java province. In this study, samples were taken as many as 100 people using purposive sampling technique, namely sampling based on criteria, among others: employees who are taken as samples are employees who have worked for at least 3 years. The data analysis method used in this research is validity, reliability, multiple linear regression, $t$ test. The results show that with multiple linear regression analysis, it can be shown by the regression equation $Y=-0.16 X 1+0.862 X 2+e 1$. From the results of the analysis above, it can be concluded that the variables of recruitment and career development do not increase, which affects work motivation. while the regression equation analysis $Y 2=0.506 X 3+0.271 Y 1+e 2$ from the results of the analysis above, it can be concluded that discipline and motivation variables increase, affect performance. The hypothesis that has been carried out in this study can be concluded that: $a$. There is a positive and significant effect of recruitment on motivation. $b$. There is a positive and significant effect of career development on motivation. $c$. There is a positive and significant effect of work discipline on performance. $d$. There is a positive and significant influence of motivation on performance in Dinakertrasduk Povinsi Central Java. Suggestions that can be put forward in this study include: company leaders to pay attention to things that can increase employee motivation and performance, among others: to further promote career development of employees of Dinakertrasduk, Central Java Province. and improve work discipline of the employees of the Central Java Province Dinakertrasduk. and pay attention to the work motivation of its employees.
\end{abstract}

Keywords: recruitment, career development, work discipline, work motivation, employee performance

\section{PENDAHULUAN}

Sumber Daya Manusia merupakan faKtor yang utama di dalam perusahaan baik di Instansi Negeri maupun Swasta, oleh karena itu pegawai berperan aktif dalam kegiatan operasional dalam mewujudkan tujuan perusahaan. Pegawai yang ada dalam suatu perusahaan sangat menentukan berkembangnya perusahaan.

Menurut Anwar Prabu (2001) bahwa kinerja adalah hasil kerja secara kualitas dan kuantitas yang dicapai oleh seorang karyawan dalam melaksanakan tugasnya sesuai dengan tanggung jawab yang diberikan kepadanya. Dalam meningkatkan kinerja pegawai instansi menempuh beberapa cara misalnya melalui perekrutan yang sesuai dengan job des, pengembangan karir, disiplin dan pemberian motivasi yang sudah ditentukan. 
Adapun yang mempengarui pencapaian kinerja terdiri dari banyak faktor, diantaranya yaitu gaji, kepuasan kerja dan disiplin kerja. Salah satu alasan seorang karyawan bekerja yaitu memperolah imbalan atau gaji yang diterimanya sehingga karyawan menjadi termotivasi dalam bekerja. Motivasi merupakan dorongan kerja yang dimiliki oleh karyawan untuk melaksakan tugas-tugasnya sesuai dengan yang diharapkan oleh atasan.Dengan adanya motivasi kerja menjadikan sesuatu pekerjaan menjadi lebih sempurna. Sebagai individu maupun makhluk sosial, karyawan memiliki berbagai kebutuhan hidupnya tersebut. Apabila perusahaan dapat memenuhi kebutuhan mereka, maka karyawan akan bersedia bekerja dengan seluruh kemampuan yang dimiliki demi kemajuan perusahaan. Faktor lain yang mempengarui kinerja karyawan adalah disiplin kerja karyawan. Kedisiplinan yang ditanamkan keryawan akan sangat mempengaruhi kesungguhan karyawan dalam bekerja. Oleh karena itu, perlu upaya pemimpin untuk membuat keryawannya bekerja secara disiplin dan pemimpin tersebut juga harus dapat menunjukkan cara yang paling baik dan membantu keryawan bertindak disiplin dalam menyelesaikan tugas atau pekerjaan sehari-harinya.

Penelitihan ini merupakan replika dari beberapa penelitian. Salah satunya dilakukan oleh Joko Wahyu Endarto (2008) yang meneliti dengan judul "Pengaruh Rekruitmen, Dekruitmen dan Disiplin kerja terhadap Kinerja karyawan PT. Delta Merlin Texstiel Karangayar". Hasil penelitian menunjukkan bahwa hasil analisis rekruitmen, rekruitmen dan variabel disiplin kerja terbukti mempunyai pengaruh positif.

Di samping itu, disiplin kerja karyawan dalam hal kehadiran masih dirasakan kurang baik, Hal ini dibuktikan dengan pesensi WFO (Work From Office) pegawai yang mana masih banyaknya karyawan yang datang tidak di tahun 2019 sedangkan tanggal 29 Mei 2020 ada Surat Edaran Sekretariat Daerah Propinsi Jawa Tengah No 965/1332 tanggal 29 Mei 2020 tentang Pencegahan dan Pengendalian Covid-19 dalam pelaksanaan tugas di lingkungan pemerintah Provinsi Jawa Tengah pada masa tatanan normal. Pegawai dapat bekerja di rumah WFH (Work From Home) dengan ketentuan presensi, pakaian kerja dan melaporkan pekerjaan ke atasan, tetapi banyak karyawan yang melaksanakannya kurang baik. Dalam meningkatkan kinerja pegawai Instansi menempuh beberapa cara misalnya melalui perekrutan yang sesuai dengan job des yang pada dasarnya perekrutan Pegawai Negeri Sipil dilalui beberapa tahapan dan sangat ketat untuk uji kompetensinya akan tetapi kinerja karyawan masih kurang baik, pengembangan karir di Instansi Pemerintah sangatlah terbuka lebar tetapi banyak karyawan yang cenderung tidak ingin berkembang, disiplin memang sangatlah kurang bisa dilihat dari presensi tiap harinya dan pemberian motivasi adalah salah satunya gaji atau imbalan yang diberikan oleh karyawan yang sudah ditentukan dengan peraturan pemerintah akan tetapi karyawan juga tidak memahami dan cenderung bermalas malasan

Rendahnya disiplin kerja karyawan mengindikasikan rendahnya kinerja karyawan. Oleh karena itu, pimpinan perlu melakukan pengawasan terhadap karyawan dalam hal kedisiplinan kerja karyawan.

Tabel 1.

Presensi karyawan

\begin{tabular}{|c|c|l|c|}
\hline NO & TAHUN & \multicolumn{1}{|c|}{ KETERANGAN } & PROSENTASE \\
\hline \multirow{3}{*}{1} & \multirow{3}{*}{2019} & Masuk & $69 \%$ \\
\cline { 3 - 4 } & & Sakit & $21 \%$ \\
\cline { 3 - 4 } & & Izin & $6 \%$ \\
\cline { 3 - 4 } & & Pulang lebih awal & $4 \%$ \\
\hline \multirow{3}{*}{2} & \multirow{3}{*}{2020} & Absensi & $65 \%$ \\
\cline { 3 - 4 } & & Sakit & $20 \%$ \\
\cline { 3 - 4 } & & $\begin{array}{l}\text { Tidak melaksanakan pelaporan pekerjaan } \\
\text { (WFH) }\end{array}$ & $15 \%$ \\
\hline
\end{tabular}

Sumber: Bagian Urusan Kepegawaian 
Berdasarkan uraian tersebut di atas, berbagai fenomena terjadi di dalam kenyataannya, bahwa para pegawai DINAKERTRASDUK di indikasikan adanya kinerja pegawai yang kurang optimal, dilihat dari presentase disiplin pegawai. Oleh karena itu penelitian ini akan mengambil judul "Pengaruh Rekruitmen, Pengembangan Karir, Disiplin kerja dan Motivasi Kerja Terhadap Kinerja Karyawan Dinakertransduk Provinsi Jateng." Salah satu usaha yang dilakukan Dinakertransduk provinsi Jawa Tengah dalam meningkatkan kinerja karyawan adalah dengan memperhatikan rekuitmen, pengembangan karir,disiplin dan motivasi.

\section{Perumusan Masalah}

a. Apakah Rekruitmen memiliki pengaruh terhadap Motivasi pegawai?

b. Apakah Pengembangan Karier memiliki pengaruh terhadap Motivasi pegawai?

c. Apakah Disiplin memiliki pengaruh terhadap kinerja pegawai?

d. Apakah Motivasi memiliki pengaruh terhadap kinerja pegawai?

\section{KERANGKA TEORITIS}

\section{Kinerja Karyawan}

Penilaian kinerja keryawan atau prestasi kerja adalah proses melalui mana organisasiorganisasi mengevaluasi atau menilai prestasi kerja karyawan (Hani Handoko, 1995: 135). Setiap perusahaan selalu berharap memiliki karyawan yang berprestasi akan memberikan sumbangan yang optimal bagi perusahaan (Tho'in \& Muliasari, 2020). Dapat disimpulkan bahwa prestasi kerja merupakan hasil kerja yang dicapai oleh karyawan dalam melaksakan tugas-tugas pekerjaan yang dibebankan kepadanya. Kegunaan-Kegunaan Kinerja Karyawan antara lain: (Hani Handoko, 1995: 137).

a. Perbaikan Prestasi Kerja, Umpan balik pelaksaan kerja kemungkinan karyawan, manajer dan departemen personalia agar dapat membetulkan kegiatan-kegiatan mereka untuk memperbaiki prestasi kerja.

b. Penyelesaian Kompensasi, Evaluasi prestasi kerja membantu para pengambilan keputusan dalam menentukan kenaikan uapah, pemberian bonus dan bentuk kompensasi lainnya.

c. Kepuasan Penempatan, Promosi, Trasfer dan demosi biasanya berdasakan pada prestasi masa lalu atau antisipasinya.promosi sering merupakan bentuk penghargaan terhadap prestasi kerja.

d. Kebutuhan-kebutuhan latihan dan pengembangan, prestasi kerja yang jelek mungkin menunjukkan potensi yang harus dikembangkan.

e. Perencanaan dan pengembangan karier, umpan balik prestasi mengarahkan keputusankeputusan karier.

\section{Disiplin Kerja}

Kedisiplinan adalah prosedur yang mengoreksi atau menghukum bawahan karena melanggar peraturan atau prosedur. Disiplin merupakan bentuk pengendalian diri karyawan dan pelaksanaan yang teratur dan menunjukkan tingkat kesungguhan tim kerja di dalam sebuah organisasi. Tindakan disiplin yang efektif terpusat pada perilaku karyawan yang salah, tidak pada karyawan sebagai pribadi (Henry Simamora, 1997:746).

Sedangkan menurut Malayu S.P. Hasibuan (2012: 193), bahwa disiplin adalah fungsi operatif dari manajemen sumber daya manusia yang terpenting karena semakin baik disiplin karyawan, semakin tinggi kinerja karja yang dapat dicapai seorang karyawan. Tanpa disiplin karyawan yang baik, sulit bagi organisasi perusahaan mencapai hasil yang optimal. Disiplin kerja yang baik mencermikan besarnya rasa tanggung jawab seseorang terhadap tugas-tugas yang diberikan kepadanya. Hal ini mendorong gairah kerja, semangat kerja, dan terwujudnya 
tujuan perusahaan, karyawan, dan masyarakat. Oleh karena itu, setiap setiap manajer selalu berusaha agar para bawahanya mempunyai disiplin yang baik.

Kebijakan disiplin memberikan organisasi kesempatan yang paling baik untuk mencapai tujuan-tujuan organisasional dan demikian menguntungkan perusahaan dan karyawan. Tindakan disiplin merupakan interaksi antar manusia. Disiplin terbagi dalam beberapa jenis antara lain (Anwar Prabu, 2001:129):

1) Disiplin Manajerial.

Dimana segala sesuatu tergantung pada pemimpin, dari permulaan hingga akhir.

2) Disiplin Tim.

Dimana kesempurnaan kinerja bermuara dari saling ketergantungan satu sama lain. Dan saling ketergantungan ini berasal dari suatu komitmen oleh setiap anggota terhadap keseluruhan organisasi kegagalan satu orang akan menjadi kebutuhan semua orang.

3) Disiplin Diri.

Dimana pelaksana tunggal sepenuhnya tergantung pada pelatihan, ketangkasan dan kondisi diri.

4) Disiplin Kerja.

Disiplin dapat pula berarti kualitas yang bernilai bagi individu yang tergantung padanya.tujuan utama tindakan disiplin adalah:

a. Memastikan bahwa perilaku-perilaku karyawan konsisten dengan atasan-atasan perusahaan. Aturan-aturan disusun untuk tujuan organisasi yang lebih jauh. Pada saat aturan dilanggar, efektivitas organisasi berkurang sampai tingkat tertentu, tergantung pada kerasanya pelanggaran. Tanpa adanya tindakan disiplin efektivitas perusahaan menjadi terbatas.

b. Menciptakan atau mempertahankan rasa hormat dan saling percaya diantara atasan dan bawahan-bawahannya. Disiplin yang diberlakukan secara tidak tepat dapat menciptakan masalah-masalah seperti moral kerja yang rendah, kemarahan dan kemauan buruk diantara atasan dan bawahannya.

\section{Rekruitmen}

Setelah diadakan perencanaan SDM dan analisis dan klafikasi pekerjaan. Maka langkah berikutnya adalah melaksanakan rekruitmen. Rekuitmen merupakan proses mencari, menemukan dan menarik para pelamar untuk dipekerjakan dalam dan oleh suatu organisasi (Gomes, 2003: 105). Maksudnya adalah untuk mendapatkan persediaan sebanyak mungkin calon-calon pelamar sehingga organisasi akan mempunyai kesempatan yang lebih besar untuk melakukan pilihan terhadap calon pekerja yang dianggap memenuhi standar kualifikasi organisasi. Menurut Husein Umar (2008: 24), rekrutmen merupakan suatu kegiatan untuk mencari sebanyak-banyaknya calon tenaga kerja yang sesuai dengan lowongan yang tersedia. Rekuitmen dilaksanakan dalam suatu organisasi karena kemungkinan adanya lowongan dengan beranekaragaman alasan, antara lain:

a. berdirinya organisasi baru.

b. adanya peluasan kegiatan organisasi.

c. terciptanya pekerjaan-pekerjaan dan kegiatan-kegiatan baru.

d. adanya pekerja yang pendah ke organisasi lain.

e. adanya pekerja yang behenti, baik dengan hormat maupun tidak dengan hormat sebagai tindakan punitive.

f. adanya pekerja yang berhenti karena memasuki usia pension.

g. adanya pekerja yang meninggal dunia.

Tenik-tenik rekuitmen, baik disektor publik maupun swata, dapat dilakukan melalui asas disentralisasikan atau didesentralisasikan, tergantung kepada keadaan organisasi, kebutuhan dan 
jumlah calon pekerja yang hendak direkrut. Faktor-faktor politik mempengarui rekuitmen karena adanya kemungkinan terjadinya perubahan dalam priolitas-prioritas program pembangunan.yang pada giliranya akan mempengarui permintaan dan penawaran relative bagi berbagai pekerjaan.

\section{Motivasi Kerja}

Motivasi adalah keadaan dalam pribadi seseorang yang mendorong keinginan individu untuk melakukan kegiatan-kegiatan tertentu guna mencapai suatu tujuan (Hani Handoko, 1994:192). Motivasi yang ada pada seseorang akan mewujudkan suatu perilaku yang diarahkan pada tujuan mencapai sasaran kepuasan. Tiap kegiatan yang dilakukan oleh seseorang didorong inilah yang disebut motivasi. Motivasi kerja adalah sesuatu yang menimbulkan dorongan atau semangat kerja atau dengan kata lain pendorong semangat kerja (Tho'in, 2018); (Martoyo, 2007:149). Motivasi kerja adalah sesuatu di dalam diri manusia yang memberi energi yang mengaktifkan dan menggerakkan ke arah perilaku untuk mencapai tujuan tertentu. Sekanto dan Hendoko mendefinisikan motivasi sebagai keadaan dalam diri pribadi seseorang yang mendorong keinginan individu untuk melakukan suatu kegiatan guna mencapai suatu tujuan (Yuli, 2005: 142).

Berdasarkan pengertian-pengertian di atas dapat ditarik kesimpulan bahwa motivasi kerja merupakan suatu dorongan yang timbul dari dalam diri seorang pegawai untuk memperoleh imbuhan dari dalam diri seorang karyawan untuk memperoleh imbalan dari perusahaan berupa gaji dan karir yang meningkat.

Motivasi kerja pegawai dapat dipengaruhi oleh hal-hal sebagai berikut (Hani Handoko, 1994:201):

a. Jaminan sosial tenaga kerja, dengan adanya jaminan sosial tenaga kerja akan lebih aman lebih sehingga motivasi kerja menjadi naik atau meningkat.

b. Kepemimpinan yang baik, karyawan akan lebih senang dan terpacu untuk kerja jika pemimpin mereka bersikap dengan baik.

c. Hubungan antar pribadi dalam perusahaan, pegawai lebih nyaman bekerja apabila mereka bisa menjaga hubungan baik dengan karyawan lain ataupun dengan pimpinan mereka.

d. Penghargaan, promosi/kenaikan pangkat, pegawai akan lebih bermotivasi dalam pekerjaan apabila mendapatkan penghargaan ataupun dapat dipromosikan.

e. Aktualisasi diri, karyawan akan mengembangkan potensi, kreativitas ataupun imajinasinya, apabila mereka bermotivasi.

f. Adanya pengarahan yang diberikan pimpinan membuat karyawan lebih bermotivasi.

g. Kondisi kerja yang menyenangkan dalam suatu perusahaan membuat karyawan senang dalam bekerja.

\section{Pengembangan Karir}

Pengembangan karir adalah suatu rangkaian (urutan) posisi atau jabatan yang ditempati seseorang selama masa kehidupan tertentu (Hadari Nawawi, 1997: 289). Sadili Samsudin (2006: 133) mendefinisikan pengembangan karir adalah suatu usaha meningkatkan kemampuan teknis, teoritis, konseptual, dan moral karyawan sesuai dengan kebutuhan pekerjaan/jabatan melalui pendidikan dan latihan. Usaha formal untuk mengubah (memanipulasi) nasib di lingkungan suatu organisasi/perusahaan itulah yang disebut pembinaan karier, sebagai salah satu kegiatan manajemen SDM. Kegiatan itu dilihat dari sudut disiplin ilmu psikologi dapat diartikan sebagai berikut:

a. Setiap individu dalam perkembangannya (pisik dan psikis), memiliki tugas perkembangan,terutama pada masa bayi, kanak-kanak dan remaja. Misalnya: setiap bayi atau anak mempunyai tugas perkembangan harus sudah mampu duduk, atau berdiri atau berbicara 
pada usia tertentu, maka anak atau remaja itu dapat dikatakan gagal atau sekurang-kurangnya terlambat dalam mewujudkan tugas perkembanganyanya.

b. Tugas perkembangan pada masa bayi, kanak-kanak dan remaja, lebih dominan dipengaruhi atau ditentukan oleh faktor kematangan baik secara phisiologis maupun psikologis. Oleh karena itu berlangsung secara alamiah, meskipun mungkin dirangsang dari luar untuk mempercepat perwujudannya.

Bertujuan untuk memperbaiki dan meninggalkan efektifitas pelaksanaan pekerjaan oleh para pekerja agar semakin mampu memberikan kontribusi terbaik dalam mewujudkan tujuan bisnis organisasi/perusahaan. Sehubungan dengan itu bagi pekerja yang dengan peningkatan, pengetahuan, keterampilan, sikapnya dan lain-lain sehingga menjadi semakin produktif, dari segi perkembangan karier akan memiliki tiga alternatif dalam perlakuan organisasi/perusahaan terhadap dirinya.ketiga alternatif itu adalah:

a. Organisasi perlu mempertahankannya pada jabatan semula, untuk jangka waktu tertentu, dengan memberikan ganjaran yang sesuai. Konsekuensinya adalah keharusan organisasi untuk melakukan perkembangan karier pada semua jenjang jabatan/posisi, karena akan selalu dihadapi keharusan mengangkat seorang pekerja untuk jabatan/posisi yang lebih tinggi, diiringi dengan keharusan mengisi jabatan/posisi yang ditinggalkannya.

b. Organisasi perlu memindahkan pekerja tersebut pada jabatan/posisi lain secara horizontal, yang lebih relevan dengan meningkatkan dan perbaikan pengetahian, keterampilan, sikap dan lain-lain yang dialami pekerja.

c. Organisasi atau perusahaan perlu mempromosikan pekerja tersebut secara vertikal atau untuk mengisi kedudukannya. Promosi ini penting karena pekerja yang memiliki kemampuan tinggi untuk suatu jabatan atau posisi, akan merupakan pemborosan jika ditempatkan pada posisi atau jabatan yang lebih rendah. Di satu sisi merupakan pemborosan yang merugikan, karena pekerja tersebut tidak terdayagunakan secara maksimal.

\section{Kerangka Pemikiran}

Alasan perusahaan melakukan rekuitmen adalah untuk menyeleksi, mencari, calon-calon karyawan baru yang ingin bekerja dengan baik sesuai dengan kemampuannya. Sehingga perusahaan atau organisasi perlu melakukan rekuitmen untuk menambah atau mengurangi kinerja karyawan yang kurang.

Motivasi kerja menjadikan suatu pekerjaan menjadi lebih sempurna sebagai individu maupun makhluk social, pegawai memiliki sebagai kebutuhan hidupnya tersebut. Apabila perusahaan dapat memenuhi kebutuhan mereka, maka pegawai akan bersedia bekerja dengan seluruh kemampuan yang dimiliki demi kemajuan perusahaan.

Disiplin kerja dalam suatu perusaahan merupakan bagian penting untuk mencapai kinerja kartyawan untuk pencapian tujuan yang diinginkan oleh suatu organisasi atau perusahaan. Kediplinan kesungguhan karyawan dalam bekerja. Pengembangan Karier dalam suatu organisasi/perusahaan sangatlah penting untuk memacu para pegawai agar pengembangan kariernya dapat sesuai dengan apa yang diinginkan oleh pegawai.

Dari pertayaan di atas, maka gambar kerangka pemikiran penilitian dapat dilihat berikut ini: 


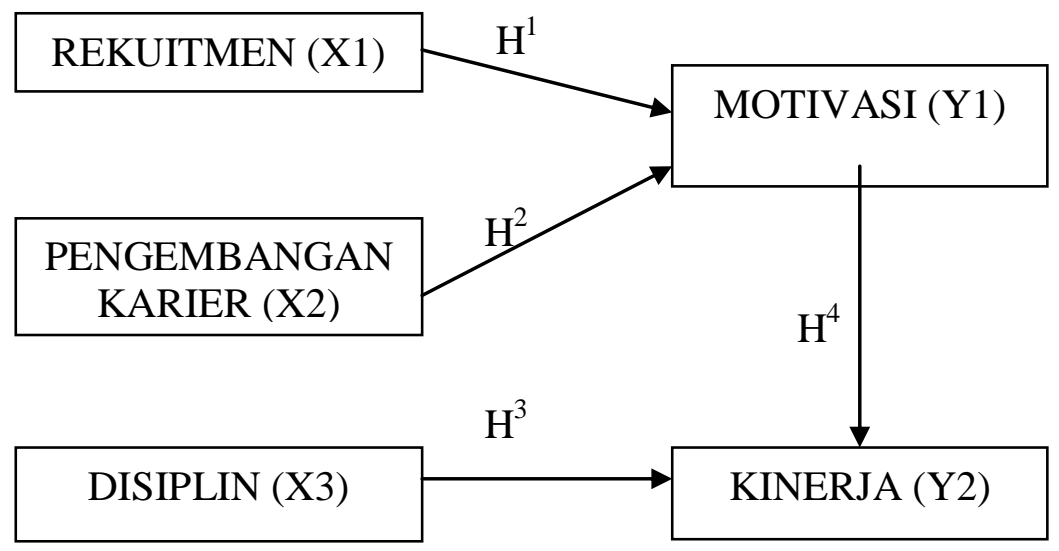

Gambar 1. Kerangka Pemikiran

\section{METODE PENELITIAN}

Metode yang digunakan dalam penelitian adalah penelitian penjelas dan explanatory yaitu tipe penelitian yang menyoroti hubungan antara variabel-variabel penelitian dan pengujian hipotesis yang telah dirumuskan. Explanatory survey adalah suatu survey yang digunakan untuk menjelaskan hubungan kausal antara dua variabel melalui pengujian hipotesis (Arikunto, 2006: 8). Dalam penelitian ini mengambil populasi pada para karyawan di Dinakertrasduk provinsi Jateng yaitu 1213 orang.

Sampel adalah sebagian atau wakil yang diteliti dalam populasi (Arikunto. 2002 : 109). Metode pengambilan sampel yaitu pengambilan sampel berdasarkan kriteria-kriteria antara lain: karyawan yang diambil sebagai sampel merupakan karyawan yang telah bekerja minimal selama 3 tahun.

Jumlah populasi diketahui yaitu 1213 orang, maka besarnya sampel yang digunakan mengacu pada pendapat Hair et.,al yang menyatakan bahwa ukuran sampel yang sesuai adalah antara $100 \mathrm{~s} / \mathrm{d} 200$. Tergantung pada jumlah indikator dan variabel yang digunakan dalam penelitian. Jumlah sampel tidak bisa dianalisis faktor jika jumlahnya kurang dari 50, sampel harus berjumlah 100 atau lebih. Sebagai aturan umum, jumlah sampel minimal adalah setidaknya 5 kali dan akan lebih diterima apabila jumlah sampelnya 10 kali dari jumlah variabel yang akan diteliti dan dianalisis (Pratita, et.al, 2018: 498). Jumlah sampel penelitian dengan analisis regresi adalah :

$$
\begin{aligned}
\mathrm{n} & =\quad(15 \mathrm{~s} / \mathrm{d} 20) \times \mathrm{V} \\
& =\quad 20 \times 5=100 \text { responden }
\end{aligned}
$$

Dimana:

$\mathrm{n}=\quad$ Sampel (konsumen yang dijadikan responden)

$\mathrm{V}=\quad$ Variabel penelitian yang digunakan

Dengan demikian jumlah sampel dalam penelitian ini sebanyak 100 responden. Menggunakan metode Purposive Sampling adalah pengambilan sampel yang dilakukan berdasarkan ciri-ciri yang sudah diketahui sebelumnya. Untuk menentukan reteria responden pendidikan minimum Deploma D3, Lama bekerja lebih dari 3 tahun.

Metode pengumpulan data menggunakan metode kuesioner. Metode kuesioner merupakan metode pengumpulan data yang dilakukan dengan cara mengharapkan responden untuk menjawab seperangkat pertanyaan atau pertanyaan tertulis, terutama dalam hal yang berkaitan dengan masalah yang teliti (Sugiyono, 2011: 93).

Analisis menggunakan uji validitas, reliabilitas, dan uji hipotesis. Sebelum dilakukan uji hipotesis terlebih dahulu dilakukan analisis factor terhadap variable penelitian penggunaan 
alat analisis ini didasarkan pada konsep interdependence techniques yaitu bagaimana nilai korelasi atau saling ketergantungan dengan indikator lainya dalam membentuk sebuah kontruk. Analisis factor dimaksudkan untuk menguji dimensasi-dimensasi dari item-item dalam variebel. Dari analisis ini diketahui nilai rasio, mengunakan analisis faktor maka item-item yang tidak valid akan dikeluarkan dari variabel penelitian. Faktor loading dilakukan dengan mengunakan analisis faktor dengan varimax rotations. Sedangkan untuk validitas masing-masing item, sebuah item dinyatakan valid apabila memiliki nilai uji $>0,4$. Uji reliabilitas untuk mengetahui sejauh mana data dapat memberikan hasil yang relative tidak berbeda bila dilakukan pengukuran kembali pada subyek persesuaian antara sesuatu yang diukur dengan jenis alat pengukur yang dipakai (Amanda et.al, 2019: 183), apapun dalam pengujian reliabilitas ini mengunakan rumus alpha. Pada pengukuran sekali saja pengukuran hanya dan kemudian hasilnya dibandingkan dengan pertayaan lain atau mengukur korelasi antar jawaban pertayaan. Diuji dengan uji statistic cronbach alpha. Suatu konstruk dikatakan reliabel jika memberikan nilai cronbach alpha $(\alpha)>0,60$. SPSS memberikan fasilitas untuk mengukur reabilitas dengan uji statistik.

Uji $\mathrm{t}$ adalah uji yang digunakan menyatakan signifikasi pengaruh variable bebas secara persial terhadap variable terkait (Duwi Priyatno, 2012: 139). Untuk menguji variabel yang berpengaruh antara rekuitmen, pengembangan karir, disiplin dan motivasi terhadap kinerja karyawan, maka dilakukan pengujian dengan t-test. Dapat dilihat pada langkah-langkah di bawah ini:

Hipotesis yang akan diuji dengan taraf nyata $=5 \%$ (uji dua arah) $\mathrm{Ho}=\mathrm{O}$ artinya tidak ada pengaruh antara rekuitmen, disiplin, terhadap kinerja karyawan secara persial (individu). H1 $=\mathrm{O}$ artinya ada pengaruh antara rekuitmen, pengembangan karir, disiplin dan motivasi terhadap kinerja karyawan.(individu).

Rumus pengujian untuk kolerasi produk moment.

$\begin{array}{ll}\mathrm{Y} 1= & \mathrm{a} 1+\mathrm{b} 1 \mathrm{X} 1+\mathrm{b} 2 \mathrm{X} 2+\mathrm{e} 1 \\ \mathrm{Y} 2= & \mathrm{a} 2+\mathrm{b} 3 \mathrm{X} 3+\mathrm{b} 4 \mathrm{Y} 1+\mathrm{e} 2\end{array}$

Dimana:

Y1 $=$ Motivasi $\mathrm{Y} 2=$ Kinerja karyawan

$\mathrm{a}=$ Konstanta $\mathrm{b}=$ Koefisien

$\mathrm{X} 1=\quad$ Rekruitmen $\mathrm{X} 2=$ Pengembangan Karier

$\mathrm{X} 3=$ Disiplin e $=$ error

\section{HASIL PENELITIAN DAN PEMBAHASAN}

\section{a. Uji Validitas}

Tabel 2

KMO and Bartlett's Test - Variabel Rekuitmen

KMO and Bartlett's Test

\begin{tabular}{|c|c|c|}
\hline Kaiser-Meyer-Ol & ure of Sampling Adequacy. & .752 \\
\hline Bartlett's Test of & Approx. Chi-Square & 178.563 \\
\hline Sphericity & Df & 6 \\
\hline & Sig. & .000 \\
\hline
\end{tabular}

Sumber: Data primer yang diolah lampiran 5

Berdasarkan tabel di atas maka dapat disimpulkan bahwa kecukupnya terhadap sample telah terpenuhi karena KMO - MSA nya 0,752 berarti jauh di atas 0,5 sedangkan signifikannya 
0,000 berarti jauh di bawah 0,05. Dengan demikian sample yang ada variable rekuitmen sudah tercukupi dan bisa dianalisis lebih lanjut.

Tabel 3

Component Matrix Variabel Rekuitmen

\begin{tabular}{|l|r|}
\hline & \multicolumn{1}{|c|}{ Component } \\
\cline { 2 - 2 } & \multicolumn{1}{|c|}{1} \\
\hline X1_1 & .887 \\
$\mathrm{X} 1 \_2$ & .770 \\
$\mathrm{X} 1 \_3$ & .842 \\
$\mathrm{X} 1 \_4$ & .810 \\
\hline
\end{tabular}

Sumber: Data primer yang diolah lampiran 5

Pengujian validitas variabel rekuitmen menggunakan analisis faktor dengan hasil yang tercantum pada tabel di atas 4.11, maka dapat dilihat bahwa ada 4 item yang digunakan untuk mengukur rekuitmen dinyatakan valid karena diatas loading factor 0,4 yaitu berkisar antara 0,770 sampai 0,887, sehingga disimpulkan bahwa rekuitmen (X1) dan sampel yang dipilih sudah layak lebih lanjut.

Tabel 4

KMO and Bartlett's Test - Pengembangan Karir

KMO and Bartlett's Test

\begin{tabular}{|c|c|c|}
\hline Kaiser-Meyer-OI & ure of Sampling Adequacy. & .78 \\
\hline Bartlett's Test of & Approx. Chi-Square & 342.25 \\
\hline Sphericity & Df & \\
\hline & Sig. & \\
\hline
\end{tabular}

Sumber: Data primer yang diolah lampiran 5

Berdasarkan tabel di atas maka dapat disimpulkan bahwa kecukupnya terhadap sample telah terpenuhi karena KMO - MSA nya 0,788 berarti jauh di atas 0,5 sedangkan signifikannya 0,000 berarti jauh di bawah 0,05 . Dengan demikian sample yang ada variable pengembangan karir sudah tercukupi dan bias dianalisis lebih lanjut.

Tabel 5

Component Matrix Variabel Pengembangan Karir

\begin{tabular}{|l|r|}
\hline & \multicolumn{2}{|c|}{ Component } \\
\cline { 2 - 2 } & \multicolumn{1}{|c|}{1} \\
\hline X2_1 & .770 \\
X2_2 & .881 \\
X2_3 & .825 \\
X2_4 & .860 \\
X2_5 & .881 \\
\hline
\end{tabular}

Sumber: Data primer yang diolah lampiran 5 
Pengujian validitas variabel pengembangan karir menggunakan analisis faktor dengan hasil yang tercantum pada tabel di atas 4.13, maka dapat dilihat bahwa ada 5 item yang digunakan untuk mengukur pengembangan karir dinyatakan valid karena diatas loading factor 0,4 yaitu berkisar antara 0,770 sampai 0,881, sehingga disimpulkan bahwa pengembangan karir (X2) dan sampel yang dipilih sudah layak lebih lanjut.

Tabel 6

KMO and Bartlles's Test - Disiplin

\begin{tabular}{|c|c|c|}
\hline \multicolumn{2}{|c|}{ Kaiser-Meyer-Olkin Measure of Sampling Adequacy } & .800 \\
\hline Bartlett's Test of & Approx. Chi-Square & 220.815 \\
\hline Sphericity & Df & 10 \\
\hline & Sig. & .000 \\
\hline
\end{tabular}

Sumber : Data primer yang diolah lampiran 5

Berdasarkan table di atas maka dapat disimpulkan bahwa kecukupnya terhadap sample telah terpenuhi karena KMO - MSA nya 0,800 berarti jauh di atas 0,5 sedangkan signifikannya 0,000 berarti jauh di bawah 0,05 . Dengan demikian sample yang ada variable disiplin sudah tercukupi dan bias dianalisis lebih lanjut.

Tabel 7

Component Matrix Variabel Disiplin

\begin{tabular}{|l|r|}
\hline & \multicolumn{2}{|c|}{ Component } \\
\cline { 2 - 2 } & \multicolumn{1}{|c|}{1} \\
\hline X3_1 & .802 \\
X3_2 & .659 \\
X3_3 & .834 \\
X3_4 & .870 \\
X3_5 & .793 \\
\hline
\end{tabular}

Sumber: Data primer yang diolah lampiran 5

Pengujian validitas variabel disiplin menggunakan analisis faktor dengan hasil yang tercantum pada tabel di atas 4.16, maka dapat dilihat bahwa ada 5 item yang digunakan untuk mengukur pengembangan karier dinyatakan valid karena diatas loading factor 0,4 yaitu berkisar antara 0,659 sampai 0,834, sehingga disimpulkan bahwa disiplin (X3) dan sampel yang dipilih sudah layak lebih lanjut.

Tabel 8

KMO and Bartlett's Test - Disiplin

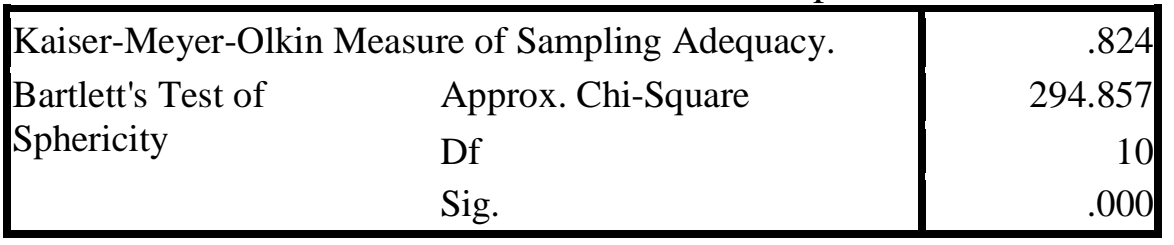

Sumber: Data primer yang diolah lampiran 5

Berdasarkan table di atas maka dapat disimpulkan bahwa kecukupnya terhadap sample telah terpenuhi karena KMO - MSA nya 0,824 berarti jauh di atas 0,5 sedangkan signifikannya 
0,000 berarti jauh di bawah 0,05 . Dengan demikian sample yang ada variable motivasi sudah tercukupi dan bias dianalisis lebih lanjut.

Tabel 9

Component Matrix Variabel Motivasi

\begin{tabular}{|l|r|}
\hline & \multicolumn{2}{|c|}{ Component } \\
\cline { 2 - 2 } & \multicolumn{1}{|c|}{1} \\
\hline Y1_1 & .904 \\
Y1_2 & .545 \\
$Y 1 \_3$ & .856 \\
$Y 1 \_4$ & .895 \\
$Y 1 \_5$ & .860 \\
\hline
\end{tabular}

Sumber: Data primer yang diolah lampiran 5

Pengujian validitas variabel motivasi menggunakan analisis faktor dengan hasil yang tercantum pada tabel di atas, maka dapat dilihat bahwa ada 5 item yang digunakan untuk mengukur motivasi dinyatakan valid karena diatas loading factor 0,4 yaitu berkisar antara 0,545 sampai 0,904, sehingga disimpulkan bahwa motivasi (Y1) dan sampel yang dipilih sudah layak lebih lanjut.

Tabel 10

KMO and Bartlett's Test - Kinerja

\begin{tabular}{|c|c|c|}
\hline & \\
\hline & \\
\hline & & \multirow{2}{*}{$\begin{array}{r}.809 \\
244.262 \\
10 \\
.000\end{array}$} \\
\hline & $\begin{array}{ll}\text { Bartlett's Test of } & \text { Approx. Chi-Square } \\
\text { Sphericity } & \text { Df } \\
& \text { Sig. }\end{array}$ & \\
\hline
\end{tabular}

Sumber: Data primer yang diolah lampiran 5

Berdasarkan table di atas maka dapat disimpulkan bahwa kecukupnya terhadap sample telah terpenuhi karena KMO - MSA nya 0,809 berarti jauh di atas 0,5 sedangkan signifikannya 0,000 berarti jauh di bawah 0,05 . Dengan demikian sample yang ada variable kinerja sudah tercukupi dan bias dianalisis lebih lanjut.

Tabel 11

Component Matrix Variabel Kinerja

\begin{tabular}{|l|r|}
\hline & \multicolumn{2}{|c|}{ Component } \\
\cline { 2 - 2 } & \multicolumn{1}{|c|}{1} \\
\hline Y2_1 & .873 \\
Y2_2 & .806 \\
Y2_3 & .674 \\
Y2_4 & .823 \\
Y2_5 & .850 \\
\hline
\end{tabular}

Sumber: Data primer yang diolah lampiran 5 
Pengujian validitas variabel kinerja menggunakan analisis faktor dengan hasil yang tercantum pada tabel di atas 11, maka dapat dilihat bahwa ada 5 item yang digunakan untuk mengukur motivasi dinyatakan valid karena diatas loading factor 0,4 yaitu berkisar antara 0,674 sampai 0,873, sehingga disimpulkan bahwa kinerja (Y2) dan sampel yang dipilih sudah layak lebih lanjut.

\section{b. Uji Reliabilitas}

Reliabilitas adalah indeks yang menunjukkan sejauh mana suatu alat ukur dapat dipercaya atau dihandalkan. Hasil perhitungan reliabilitas adalah sebagai berikut:

Tabel 12

Hasil Pengujian Reliabilitas

\begin{tabular}{|l|c|c|c|}
\hline \multicolumn{1}{|c|}{ Variabel } & Cronbach's Alpha & Kriteria Uji & Ket \\
\hline Rekuitmen (X1) & 0,847 & 0,6 & Reliabel \\
\hline Pengembangan Karir (X2) & 0,889 & 0,6 & Reliabel \\
\hline Disiplin Kerja (X3) & 0,852 & 0,6 & Reliabel \\
\hline Motivasi (Y1) & 0,869 & 0,6 & Reliabel \\
\hline Kinerja (Y2) & 0,857 & 0,6 & Reliabel \\
\hline
\end{tabular}

Sumber: Data primer yang diolah lampiran 6

Dari tabel pengujian diperoleh hasil yang menunjukan Cronbach's Alpha dan Kriteria Uji $(0,6)$ sehingga dapat disimpulkan bahwa variabel - variabel yang dipakai dalam penelitian ini adalah reliabel. Dengan demikian maka jelaslah bahwa variabel - variabel tersebut dapat digunakan untuk penelitian selanjutnya karena dapat diandalkan.

\section{c. Analisis Data}

Tabel 13

Ringkasan Analisis Regresi

Coefficients $^{\text {a }}$

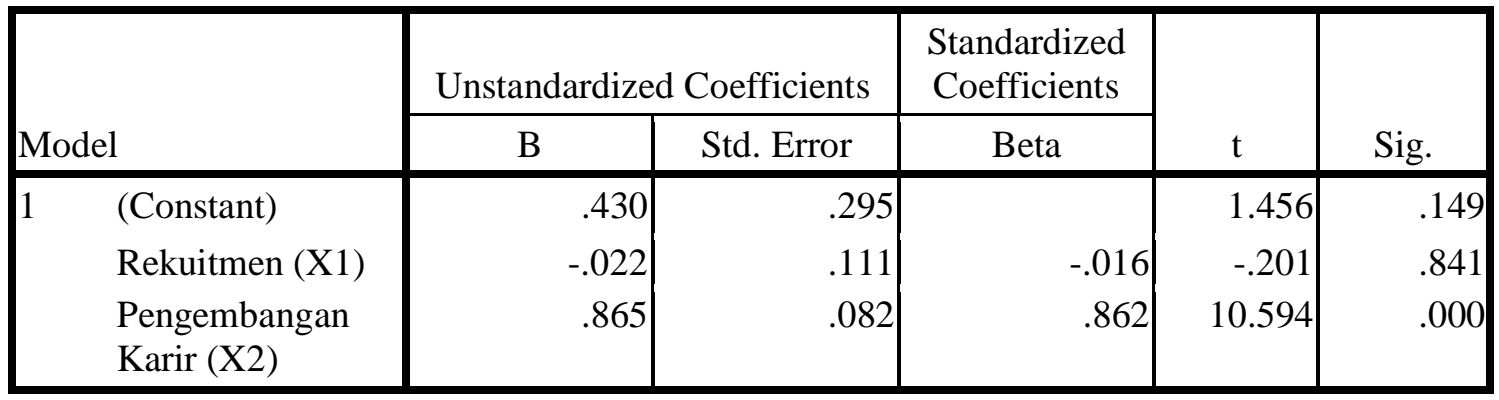

a. Dependent Variable: Y1_mean

Sumber: Data primer yang diolah lampiran 7

Dalam menganalisis dari perhitungan regresi berganda menggunakan nilai koefisisn regresinya menggunakan hasil yang berstandar (Standardized Coefficients), sehingga bisa dimasukan dalam persamaan sebagai berikut:

$$
\mathrm{Y} 1=-\mathbf{0 , 1 6 X 1}+\mathbf{0 , 8 6 2 X 2}+\mathrm{e} 1
$$

Dari persamaan regresi berganda di atas,untuk variable rekuitmen koefisisn nilai regresinya sebesar -0,16 dan bertanda (-).ini artinya variable rekuitmen tidak meningkat, membuktikan 
bahwa tidak berpengaruh terhadap motivasi. Untuk variabel pengembangan karir koefisien regresinya sebesar 0,862 dan bertanda (+). Ini artinya setiap variabel pengembangan karir meningkat, membuktikan bahwa berpengaruh terhadap motivasi.

Tabel 14

Ringkasan Analisis Regresi

Coefficients $^{\mathrm{a}}$

\begin{tabular}{|c|c|c|c|c|c|c|}
\hline \multirow{2}{*}{\multicolumn{2}{|c|}{ Model }} & \multicolumn{2}{|c|}{ Unstandardized Coefficients } & \multirow{2}{*}{$\begin{array}{c}\text { Standardized } \\
\text { Coefficients }\end{array}$} & \multirow[b]{2}{*}{$\mathrm{t}$} & \multirow[b]{2}{*}{ Sig. } \\
\hline & & $\mathrm{B}$ & Std. Error & & & \\
\hline 1 & (Constant) & 3.139 & 1.128 & & 2.781 & .007 \\
\hline & Disiplin (X3) & .589 & .070 & .588 & 8.477 & .000 \\
\hline & Motivasi (Y1) & .252 & .052 & .339 & 4.895 & .000 \\
\hline
\end{tabular}

a. Dependent Variable: Y2_tot

Sumber: Data primer yang diolah lampiran 7

Dalam menganalisis dari perhitungan regresi berganda menggunakan nilai koefisisn regresinya menggunakan hasil yang berstandar (Standardized Coefficients), sehingga bisa dimasukan dalam persamaan sebagai berikut:

$$
\mathrm{Y} 2=0,588 \mathrm{X} 3+0,339 \mathrm{Y} 1+\mathrm{e} 2
$$

Dari persamaan regresi berganda di atas,untuk variable disiplin koefisisn nilai regresinya sebesar 0.588 dan bertanda (+).ini artinya variable disiplin meningkat, membuktikan bahwa berpengaruh terhadap kinerja. Untuk variabel motivasi koefisien regresinya sebesar 0,339 dan bertanda (+). Ini artinya setiap variabel motivasi meningkat, membuktikan bahwa berpengaruh terhadap kinerja.

\section{d. Hasil Pengujian Hipotesis (Uji t)}

\section{Uji Hipotesis 1}

Dari table diatas diperoleh koefisisen regresi variable rekuitmen beta standardized coefficients sebesar $-0,16$ dan signifikansinya 0,841. Artinya dengan signifikasi yang lebih dari 0,05 dan koefisiensinya bertanda negative berarti membuktikan bahwa pengaruh rekuitmen terhadap motivasi pegawai pada Dinakertrasduk Provinsi Jateng berpengaruh atau hipotesis 1 tidak diterima.

\section{Uji Hipotesis 2}

Dari tabel di atas diperoleh koefisien redresi variable pengembangan karir beta standardized coefficients sebesar 0,862 dan signifikansinya 0,000. Artinya dengan signifikansi yang jauh di bawah 0,05 dan koefisiennya bertanda positif berarti membuktikan bahwa pengaruh pengembangan karir terhadap motivasi pegawai Dinkertrasduk Provinsi Jateng terbukti atau hipotesis 2 diterima

\section{Uji Hipotesis 3}

Dari tabel diperoleh koefisien regresi variable disiplin kerja beta standardized coefficients sebesar 0,588 dengan t hitung sebesar 8,477 dan signifikansinya 0,000. Artinya dengan signifikansi yang jauh diatas 0,05 dan koefisiennya bertanda positif berarti membuktikan bahwa pengaruh disiplin kerja terhadap kinerja pegawai Dinakertrasduk Provinsi Jateng terbukti atau hipotesis 3 diterima. 


\section{Uji Hipotesis 4}

Dari tabel diperoleh koefisien regresi variable motivasi kerja beta standardized coefficients sebesar 0,339 dengan t hitung sebesar 4,895 dan signifikansinya 0,000. Artinya dengan signifikansi yang jauh diatas 0,05 dan koefisiennya bertanda positif berarti membuktikan bahwa pengaruh disiplin kerja terhadap kinerja pegawai Dinakertrasduk Provinsi Jateng terbukti atau hipotesis 4 diterima.

\section{PENUTUP}

\subsection{Simpulan}

Berdasarkan hasil penelitian pada bab sebelumnya,maka dapat diambil beberapa kesimpulan sebagai berikut :

a. Secara keseluruhan variabel yang diuji, yaitu rekuitmen, pengembangan karir, disiplin, motivasi dan kinerja yang dipersepsikan responden atau pegawai Dinakertrasduk Provinsi Jateng dapat dikatakan cukup baik. Hal ini ditunjukkan pada diskripsi variabel responden yang menjawab setuju dan netral pada hampir item-item pertanyaan.

b. Hipotesis yang telah dilakukan dalam penelitian ini menyatakan :

1) Hipotesis I : ditolak, artinya tidak ada pengaruh positif antara rekruitmen dengan kinerja.

2) Hipotesis II : diterima, artinya ada pengaruh positif antara pengembangan karier dengan kinerja.

3) Hipotesis III : diterima, artinya ada pengaruh positif antara disiplin kerja dengan kinerja

4) Hipotesis IV : diterima, artinya ada pengaruh positif antara motivasi dengan kinerja

\subsection{Saran}

Dari kesimpulan diatas, maka penulis berusaha memberikan saran-saran yang dapat ditemukan untuk kemajuan di masa akan datang, adalah sebagai berikut:

a. Pada saat dilakukan rekruitmen sebaiknya organisasi lebih selektif dalam melakukan seleksi penarikan karyawan sehingga diharapkan organisasi memiliki pegawai yang berkompeten di bidangnya untuk mencapai tujuan organisasi secara optimal.

b. Disiplin kerja mempunyai pengaruh yang cukup dominan terhadap kinerja sehingga diharapkan pegawai mampu mempertahankan bahkan meningkatkan disiplin kerja uang sudah tercipta.

c. Organisasi dapat memberikan peluang atau kesempatan kepada semua pegawai tanpa terkecuali sehingga mereka dapat mengembangkan karier agar mampu berkinerja dengan lebih baik lagi.

d. Dalam motivasi diharapkan organisasi dapat memberikan perhatian dan penghargaan terhadap pegawai berprestasi agar pegawai lainnya akan termotivasi untuk bekerja lebih baik lagi.

\section{DAFTAR PUSTAKA}

Amanda, L; Yanuar, F; \& Devianto, D. (2019). Uji Validitas Dan Reliabilitas Tingkat Partisipasi Politik Masyarakat Kota Padang, Jurnal Matematika UNAND, 8(1).

Arikunto, S. (2002). Prosedur Penelitian Suatu Pendekatan Praktek.Jakarta: Rineka Cipta.

Arikunto, S. (2006). Prosedur Penelitian Suatu Pendekatan Praktek. Edisi Revisi VI. Jakarta : Rineka Cipta.

Gomes, F C. (2003). Manajemen Sumber Daya Manusia. Yogyakarta: CV. Andi Offset. 
Handoko, T. H. (1994). Metode-metode Penilaian Kinerja. Yogyakarta : BPFE.

Handoko, T. H. (1995). Manajemen. Yogyakarta: BPFE.

Hasibuan, M. S.P. (2012). Manajemen Sumber Daya Manusia. Jakarta: PT Bumi. Aksara.

Mangkunegara, A.A. A P. (2001), Manajemen sumber daya manusia perusahaan, Bandung: Remaja Rosdakarya.

Martoyo, S. (2007). Manajemen Sumber Daya Manusia, Edisi 5, Cetakan Pertama. Yogyakarta: BPFE.

Nawawi, H. (1997). Manajemen Sumber Daya Manusia Untuk Bisnisyang Kompetitif, Yogyakarta: Gajah Mada University-Press.

Pratita, B W A; Pratikto, H; \& Sutrisno. (2018). Analisis Faktor-Faktor yang Memengaruhi Keputusan Pembelian Pelanggan di Kober Bar Malang, Jurnal Pendidikan: Teori, Penelitian, dan Pengembangan, Vol. 3 No. 4.

Priyatno, D. (2012). Cara Kilat Belajar Analisis Data dengan SPSS 20. Edisi Kesatu. Yogyakarta: ANDI.

Samsudin, S. (2006). Manajemen Sumber Daya Manusia, cetakan ke-1. Bandung : Pustaka Setia.

Simamora, H. (1997). Manajemen Sumber Daya Manusia, Yogyakarta: STIE YKPN.

Sugiyono. (2011). Metode Penelitian Kuantitatif, Kualitatif dan R\&D. Bandung: Afabeta.

Tho'in, M. (2018). Effects of Training, Work Discipline, and Motivation Against Employee Performance at Islamic Bank. Jurnal Ekonomi dan Bisnis Islam, 3(2), 131-143.

Tho'in, M., \& Muliasari, D. (2020). Analysis of Work Satisfaction, Organizational Commitments, and Work Engagement Efffect Toward Employee Performance in Sharia Banks. International Journal of Economics, Business and Accounting Research (IJEBAR), 4(02).

Umar, H. (2008). Desain Penelitian MSDM Dan Prilaku Karyawan Paradigma Positvistik dan Berbasis Pemecahan Masalah. Jakarta: PT. Raja Grafindo Graha.

Yuli, S B C. (2005). Manajemen Sumber Daya Manusia, Malang: UMM Press. 